\title{
Introduction to Special Issue on Personal Essays in Social Science
}

\author{
Pooja Sawrikar*(D) and Donna McAuliffe \\ School of Human Services and Social Work, Logan Campus, Griffith University, Meadowbrook, QLD 4131, \\ Australia; d.mcauliffe@griffith.edu.au \\ * Correspondence: p.sawrikar@griffith.edu.au
}

Received: 28 November 2019; Accepted: 29 November 2019; Published: 2 December 2019

\section{Background}

Dear colleagues,

I called this Special Issue because three of my own personal essays (Sawrikar 2018a, 2018b, 2018c) were rejected 18 times between them by scholarly journals. Yet, I was a 41 year old academic with nothing but academic experience - having gone straight from school, to undergrad, to postgrad, to teaching and research in higher education. This is the only professional life and industry I have ever known. As would be expected, my writing got better with time and age (according to my standards of course, not anyone else's), but for some reason my best writing was seeing a shut door.

The reason I believe my writing improved over those years was because I started to move from my head and into my gut. In my head, I intellectualised and rationalised my feelings to the point where I left myself confused. In my centred diaphragmatic gut, I just spoke-authentically, honestly, truthfully, and because of a driving force for social justice, ethically. Don't get me wrong, I still value what's happening in my head, but what has changed is that I do not value it more than knowledge derived from other means. Until that transition had taken full effect, my profession successfully had me believe, and be deceived by, a falsity: that feelings were to be made sense of with a rational mind. As I begin middle-age, I make a choice to do academia differently. I make the choice to trust that feelings are rational. They know exactly what they're doing. They use a lifetime of tacit and explicit knowledge and experience to help guide our next move. And at the end of the day, our lives are just a series of the next move we played. It is wholly worthy of honouring, as is.

As the rejections to my three papers came in, a feeling emerged: that speaking as a person was deemed unscientific; a mere opinion. But science is about the pursuit of truth, and how we go about it influences what we'll find; our method is linked with our discoveries. Different processes lead to different outcomes. In qualitative research-its own revolution against positivism across the evolving history of the scientific method-we ask others how they feel about things to help work out 'what's really going on'. But for some deeply biased reason, we are not really allowed to ask ourselves the same question. Conscious of the fact that my next sentence does not want to but does essentialise gender: this bias systematically silences womyn in academia. When we speak with our voice, we are dismissed. In this way, we are not seen to be true knowledge-bearers.

Audre Lorde (1984) famously said, "those of us who stand outside the circle of society's definition of acceptable women; who have been forged in the crucibles of difference-those who are poor, lesbians, Black, older-know that survival is not an academic skill. It is learning how to take our differences and make them strengths. For the master's tools will never dismantle the master's house. They may allow us temporarily to beat him at his own game, but they will never enable us to bring about genuine change. And this fact is only threatening to those women who still define the master's house as their only source of support" (p. 113). 
There are many academics already in this space-writing memoirs and manifestos as a means for understanding the nature of the world. This Special Issue is simply adding its small contribution, to help build momentum and critical mass for a new revolution; one that divorces itself from the "master's house" and redefines for itself what truth is allowed to look like. In this revolution, social scientists travel full circle to come back to one of the purist and naturally occurring forms of knowledge-production-introspection. But having now travelled and explored the many forms that science can take, this time the introspection is done with intention and awareness that while it has its limits as a method in the pursuit of truth, those limits are no worse than the limits of quantitative or qualitative research. Quantitative research searches for objective truth independent of the mind's workings, and qualitative research strives to co-produce subjective truth with its participants. Introspection values the academic as both a professional and a person.

I invited my colleague, Professor Donna McAuliffe, to be a co-editor because of her long-standing experience and wisdom in this academic business, and to help me distill what each paper in this Special Issue brings to the collection. Our summarises are below.

\section{Summaries}

Dr. Michelle Newcomb writes a powerful essay of how class history shapes experiences of becoming a social worker, and receiving recognition through permanency in employability. The honesty is palpable, and her awareness and care to not shame the organisations that have excluded her in the past are a testament to her social work virtue of integrity. She is aware that things are on the line for her, but is both brave and ethical as she speaks her truth. Taking the time to articulate the class tensions between Human Services and Social Work will surely resonate for those who have walked in similar shoes. A call for deep reflection on how lived and professional experience outside the bureaucratic checkboxes can truly be honoured and valued is a worthwhile call indeed, and Michelle offers grounded and founded suggestions on how to move forward in ways that align with the values of the social work profession. I hope her moving personal essay begins a real shake-up in what appropriate professional social work standards and expectations for accreditation, field placement, and self-care should be. Doing so, can help loosen "tight shoes".

Hilary Gallagher, Liuqing (Molly) Yang, and Dr. Jianqiang (Joe) Liang present a stimulating and compelling read, consisting of a series of email exchanges between an Australian social work educator and a Chinese social work student, informed by a Chinese critical friend. Many contemporary issues relating to the social work profession are explored with in-depth critical reflection, and heartening honesty about the barriers faced in both countries to developing the value of the profession. Cultural differences and the drive for decolonised practice are respected and honoured, but as readers witness the unfolding bidirectional learning and growth that comes from the exchange, they are left feeling more with a sense of sharedness than difference across East/West contexts. Themes of low salaries for highly complex work, burnout and compassion fatigue, and bureaucratised paper-pushing, add to the growing call for greater value for the profession. If its value amasses, maybe then on New Year's Day, instead of asking about how much money was earned, someone may ask "how many people did you help this year?"

Dr. Hyacinth Udah writes with the powerful, brave, and heart-breaking voice of a Black Australian; something that otherwise remains invisible. Had he not penned this short account of what is a much longer life story, the devalued labour and contribution to Australian society of those with the 'wrong skin colour', in a system that both overtly and covertly oppresses and excludes the racialised other, would continue to go unsaid. The gap between feeling Australian, but not being seen by others as Australian, and the heart-wrenching desire for that gap to be bridged with the warmness of humanity, is a call for all white Australians to wake up from their privileged slumber. Ignorance is banal for those who do not live every day with racial injustice, but an eventually completely wearying accumulation of disappointment across the lifespan for those who do. There is a window of opportunity to embrace each other before that happens, and this paper is a call for that opportunity to be seized. (It's a shame 
though, that that window "depends on the goodwill of the dominant Australian majority", as it only affirms their hegemony).

Dr. Mim Fox, with her careful choice of analytic rather than evocative autoethnography, tracks a beautifully human journey of practitioner, to researcher, to practice-based researcher, where the reader is taken on the swing of the professional pendulum until it finally subsides to a point somewhere in the middle. Using her own experiences to foreground the challenges of working as a social worker in hospital settings, and the consequent escape to academia for one-step-removed respite and recovery, she now finds herself at the peak of job satisfaction bridging the two end-points. Readers strong on the value for participatory research, and power-sharing knowledge and expertise with management, will particularly appreciate affirmation of these important messages, as they will for the "act and art" of storytelling. She names what typically goes unsaid: that the impact of compassion fatigue and vicarious trauma is denied by the profession; chalked up as an inevitable part of the business. This leaves a vacancy in both personal accounts of what it looks like so that others may be able to see their reflection and feel shared comfort and validation, and of professional accountability for the care, wellbeing, and resilience of its workforce. Following up when social work practitioners leave hospital settings and revising curricular before they enter it, are grounded recommendations worth heeding.

Dr. Eva Sánchez-Teba, with her colleague in ethnography Dr. Guillermo Bermúdez-González who lends additional scholarly expertise, writes a fascinating reflective piece about whether technologically savvy 'smart cities' truly enact citizen- and enviro-centricity in the way they claim to pursue, or whether this term has become trendy blurry rhetoric that public administrators know they should sprout without having any real clear understanding of how the pursuit came to be. In straddling the dual positions of public manager and doctoral student in this relatively new research space, age-old tensions had the chance to take on even richer meaning: the disjunct between theory and practice particularly amidst "complex, progressive, and utopian" ideals; bureaucratic blaming, power, and leadership dynamics amidst desires for co-creation, cohesion, and inclusivity; and the issue of scale-working with 'big data' to produce that invisible feeling of quality of life as one ambles through familiar streets. This essay brings to attention the "freedom" that autoethnography gives scholars, and the very use of the word creates a feeling of liberation for its readers too; the constant pressure that comes with facing the charge that subjectivity is not a real means for truth-finding has the chance to ease.

Dr. Adriana Gil-Juárez brings her pages of writing to life with more than thirty years of rich heartful professional experience in academia to reflect on. It is an attention-grabber from the outset, and poetically paints a picture that so many of us in this industry relate to; the picture of both sheer helplessness as well as flickers of possibly tokenistic hope that neoliberalism forces us to draw. If ever there was a personal essay to read on how damaging neoliberalism has been for academia and academics, this is it. Her articulation of the strengths of autobiographical, narrative, life story, truth telling, truth finding - however we'd like to call these things-are also phenomenal. Students early in their learning of this method of inquiry gain a beautiful benchmark of how it looks when it ripens and sophisticates across the lifespan. The lived experience of being forced to be an "academic refugee" due to so few permanent positions being available, and accreditation requirements in the Iberian context coming to feel never-ending, is documented with the depth and detail required to see what this actually looks like across one's long-standing career. She calls out the cruel trick that neoliberalism plays by co-opting the very words that academia once stood for-creativity, innovation, flexibility, plurality, autonomy, quality, and transparency. It can leave you feeling foolish and sad.

\section{Peer Review}

Growing concerns over the conservatism of intellectual thought and debate as a result of neoliberalism is being voiced by academics who seek 'academic freedom' within a broader value for freedom of lawful and ethical speech (see Report of the Independent Review of Freedom of Speech in Australian Higher Education Providers; "French Code/Review" (French 2019)). Note: these academics are being distinguished from those of the far-right, who support freedom of speech without regard 
for the consequences to the well-being of people and groups who do not systematically benefit from hundreds of years of acquired white and male privilege off the oppression and violence of others; an advantage they wish to maintain. The toxic 'publish or perish' environment can cause both authors and editors to err on the side of caution; writing papers likely to get published, with low liability for backlash due to 'informed opinions' being seen as diametrically opposed to 'empirical rigour' - an age-old conflation between objectivity and subjectivity that humans struggle to get past. (Until knowledge, at least in the social sciences, is understood as the movement from 'opinion' to 'informed opinion', it will remain undervalued). Academics, journals, and universities all have a vested interest in rejecting or minimising such concerns, but the validity of those naming the issue remains.

To help counter the trend, the following blurb was sent to all reviewers, as a reminder for them to not carelessly abuse their power and privilege, but rather to use it responsibly with kindness: You are invited to review a manuscript that has been submitted to Social Sciences. This manuscript has been submitted to a Special Issue on Personal Essays in Social Science. If you agree to review this paper, please read the Call for this Special Issue first (https://wwww.mdpi.com/journal/socsci/special_issues/personal_essays) to gain an understanding of its purpose and the criteria for peer review. Through critical and personal reflection, the expression of new ideas are being sought and encouraged. Thus, reviewers are asked to remain mindful to not assess the degree to which they agree with the positions offered by the author but the potential contribution of their ideas to the scholarly community and intellectual debate, and opportunity to express thoughts and feelings about their experiences and therefore representation of their voice. If the manuscript meets the criteria for peer review in this Special Issue, and has good 'readability', please proceed with offering suggestions for how it may be improved.

It may also be interesting for readers to note that when reviews were unanimously positive (that is, all accepting the manuscript with no or minor changes in the first round), the author received a $50 \%$ discount on the Article Processing Charge (APC). This was negotiated with the Journal in advance to help ensure that profiteering from the traumatic injustices and ensuing wisdom of its authors did not occur. We wish to sincerely thank the Journal for its commitment to social justice, in line with its core business of disseminating (collegially-developed) knowledge in the Social Sciences.

\section{In Closing}

We wholeheartedly thank each of our contributors, from across the globe, for their time, sharing, and knowledge, and hope our readers enjoy learning from the personal reflections of their fellow social scientist scholars. Honesty, bravery, authenticity, knowledge, and truth are inextricably linked; call-cards for feminists-women and men. Nine such voices that honour this are captured in this Special Issue. We hope they help pave the way for the momentum and mass needed to ensure these vehicles for truth are genuinely valued on par with quantitative and qualitative research. When this Issue was first established, we were looking for personal narratives from all corners of academia. So, the voice of the white male was not to be privileged, but it was not to be excluded either. None took up the opportunity here, but the proverbial door remains open.

Dr. Pooja Sawrikar

Professor Donna McAuliffe

Funding: This research received no external funding.

Conflicts of Interest: The authors declare no conflict of interest.

\section{References}

French, Robert. 2019. Report of the Independent Review of Freedom of Speech in Australian Higher Education Providers. Available online: https://docs.education.gov.au/node/52661 (accessed on 30 September 2019).

Lorde, Audre. 1984. The master's tools will never dismantle the master's house. In Sister Outsider: Essays and Speeches. Berkeley: Crossing Press, pp. 110-14. 
Sawrikar, Pooja. 2018a. A Critical Reflection on Being an Ethnic Minority Researcher of Child Sexual Abuse in Ethnic Minority Communities: Implications for Social Work and Sociology. Available online: https://medium.com/@p.sawrikar/chasing-a-dream-is-racial-equality-attainable-8bcc7329402e?source= friends_link\&sk=703941d8308bbfb4ac0b418832ef98fa (accessed on 30 September 2019).

Sawrikar, Pooja. 2018b. Hypocritical Wiring and Its Limits on Empathy: The 'Sense of Agency' Bias. Available online: https://medium.com/@p.sawrikar/hypocritical-wiring-and-its-limits-on-empathy-the-sense-ofagency-bias-9b9aeaaba3b3?source=friends_link\&sk=774be8c483b91140dadedf988f889792 (accessed on 30 September 2019).

Sawrikar, Pooja. 2018c. My Double Whammy: Being a Brown Woman in Western Academia. Available online: https://medium.com/@p.sawrikar/my-double-whammy-being-a-brown-woman-in-western-academiaa36bf73e2b09? source=friends_link\&sk=3489539882af83b501fc07476b142a47 (accessed on 30 September 2019).

C 2019 by the authors. Licensee MDPI, Basel, Switzerland. This article is an open access article distributed under the terms and conditions of the Creative Commons Attribution (CC BY) license (http://creativecommons.org/licenses/by/4.0/). 